Florida International University FIU Digital Commons

\title{
A Graduate Guitar Recital Consisting of Works by Leo Brouwer and Mario Castelnuovo-Tedesco with Extended Program Notes
}

Enrique Caboverde III

Florida International University, ecabo002@fiu.edu

DOI: $10.25148 /$ etd.FI12050241

Follow this and additional works at: https://digitalcommons.fiu.edu/etd

\section{Recommended Citation}

Caboverde, Enrique III, "A Graduate Guitar Recital Consisting of Works by Leo Brouwer and Mario Castelnuovo-Tedesco with Extended Program Notes" (2012). FIU Electronic Theses and Dissertations. 640.

https://digitalcommons.fiu.edu/etd/640 
FLORIDA INTERNATIONAL UNIVERSITY

Miami, Florida

GRADUATE GUITAR RECITAL

CONSISTING OF WORKS BY LEO BROUWER

AND MARIO CASTELNUOVO-TEDESCO

WITH EXTENDED PROGRAM NOTES

A thesis submitted in partial fulfillment of the

requirements for the degree of

MASTER OF MUSIC

by

Enrique Caboverde, III

2012 
To: Dean Brian Schriner

College of Architecture and the Arts

This thesis, written by Enrique Caboverde, III, and entitled A Graduate Guitar Recital Consisting of Works by Leo Brouwer and Mario Castelnuovo-Tedesco with Extended Program Notes, having been approved in respect to style and intellectual content, is referred to you for judgment.

We have read this thesis and recommend that it be approved.

Dr. William D. Hardin

$\begin{array}{r}\hline \text { Dr. David Dolata } \\ \hline \text { Dr. Joel Galand } \\ \hline \text { Rafael M. Padron, Major Professor }\end{array}$

Date of Defense: March 22, 2012

The thesis of Enrique Caboverde, III is approved.

Dean Brian Schriner College of Architecture and the Arts

Dean Lakshmi N. Reddi University Graduate School

Florida International University, 2011 


\section{DEDICATION}

This thesis is dedicated to my beautiful wife, Amy,

for her unfailing, loving support

and occasional gentle prods. 


\section{ABSTRACT OF THE THESIS \\ GRADUATE GUITAR RECITAL CONSISTING OF WORKS BY \\ LEO BROUWER AND MARIO CASTELNUOVO-TEDESCO \\ WITH EXTENDED PROGRAM NOTES}

by

Enrique Caboverde, III

Florida International University, 2012

Miami, Florida

Professor Rafael M. Padron, Major Professor

This thesis presents extended program notes for a recorded graduate classical guitar recital consisting of the following works for solo guitar with string quartet and chamber orchestra: Mario Castelnuovo-Tedesco: Quintet for Guitar and Strings, Op. 143; Leo Brouwer: Concerto No. 3 ("Elegiaco"). Both works are pioneering and invaluable contributions to guitar literature. Tedesco's Quintet for Guitar and Strings, Op. 143 is the first quintet ever composed to properly showcase the virtuosity of the guitar within a chamber setting. Concerto "Elegiaco" demonstrates the refinement of Leo Brouwer's use of post-modern tonality and minimalism within classical form, and showcases his unique compositional style. 


\section{TABLE OF CONTENTS}

CHAPTER PAGE

I. Mario Castelnuovo-Tedesco: Quintet for Guitar and Strings, Op. 143

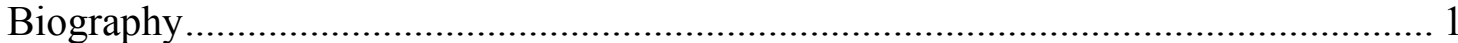

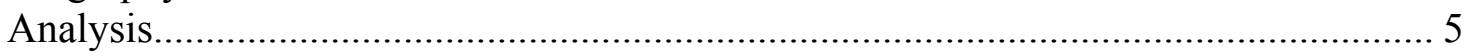

II. Leo Brouwer: Concerto No. 3, Elegiaco

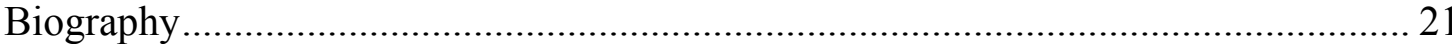

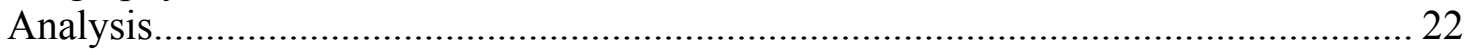

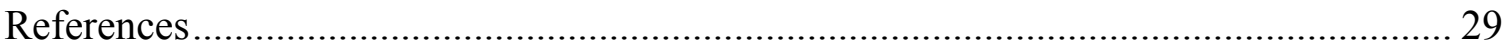




\section{LIST OF FIGURES}

FIGURE

PAGE

1. Quintet, $1^{\text {st }}$ movement. Motivic Relationship between Q, P and S.......................

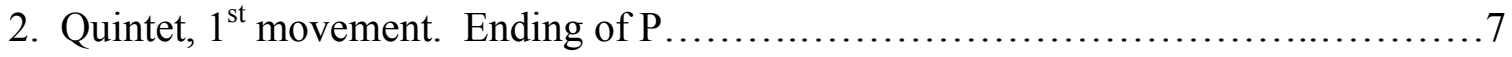

3. Quintet, $1^{\text {st }}$ movement. Cello counterstatement of S on III\#...................................

4. Quintet, $1^{\text {st }}$ movement. Harmonic plan of development...........................9

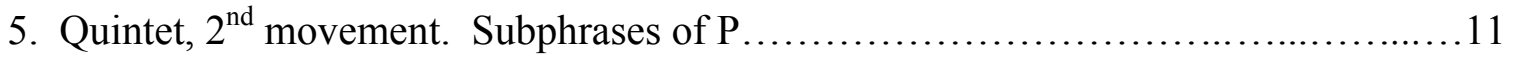

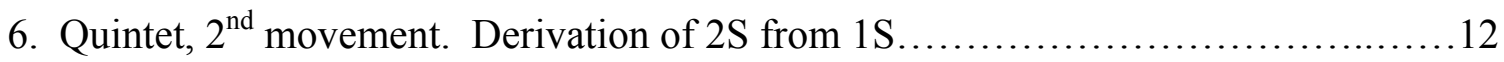

7. Quintet, $2^{\text {nd }}$ movement. Variant of $\mathrm{Pa}$ in development........................... 13

8. Quintet, $3^{\text {rd }}$ movement. Scherzo theme........................................ 14

9. Quintet, $3^{\text {rd }}$ movement. Second trio........................................ 15

10. Quintet, finale. Refrain theme........................................ 16

11. Quintet, finale. Eingang to solo refrain (mm. 29-38).......................... 16

12. Quintet, finale. Second episode........................................18

13. Quintet, finale. Second episode progression...............................18

14. Quintet, finale. Third episode.......................................... 19

15. Elegiaco. Second Movement. Orchestra mimics the guitar......................24

16. Principle of structure found in Paul Klee's works..............................25

17. Elegiaco. First Movement. m. 1 and bass reduction of mm. $57-88 \ldots \ldots \ldots \ldots \ldots \ldots . . . .25$

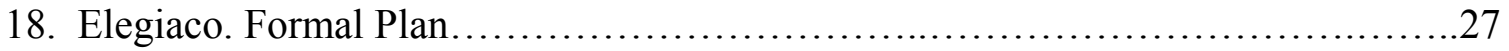




\section{Mario Castelnuovo-Tedesco: Quintet for Guitar and Strings, Op. 143}

\section{Biography}

Mario Castelnuovo-Tedesco is one of the most important twentieth-century composers for classical guitar, yet unfortunately, his gifts have been largely underappreciated. His contributions to the guitar literature are as numerous as they are original and musically substantial. His three-decade-long career as a composer of film music, however, seems to overshadow much of what he composed for the concert stage. Understanding the necessity of providing for his family, Tedesco humbly wrote: "In my garden grow green vegetables — my film music — and flowers in abundance — the music I compose for myself" (Otero 1999, 73).

Tedesco was born on April 3, 1895 to a Jewish banker, Amadeo CastelnuovoTedesco and his youthful and musically inclined wife, Noemi Senigaglia. Noemi was the opposite of Tedesco's father, who, although loving, was "very rigid, rational and reserved" (Otero, 13). His mother, on the other hand, was sanguine, affectionate, and often played the piano and sang for Tedesco and his two older brothers, Ugo and Guido. Tedesco shared a love for opera with his mother, and at a very young age was able to sing entire operas perfectly in tune with rhythmic precision. Contrary to his father's wishes, little Mario also began learning to play the piano at the age of six — an activity his father regarded suitable only for "young ladies" (Otero, 15). These clandestine classes were revealed when he chose to perform a Chopin mazurka and nocturne as well as a composition of his own, Piccolo Valser, for his father as a birthday gift. Amadeo, though displeased with the prospect of his son learning the piano, allowed nine-year-old Tedesco to continue his musical studies, but only as a pastime (Otero, 16). 
Tedesco began his formal studies under pedagogue, concert pianist and composer, Edgardo Samuel del Valle de Paz (1861-1920), and later continued them under the tutelage of Ildebrando Pizzetti (1880-1968), who became a major influence musically and personally in Tedesco's life. ${ }^{1}$ His father, staunchly resolved to rear a respectable young man, imposed the study of medicine. Tedesco served as a nurse in the military, but after a brief period of duty, a recurring and physically debilitating case of pleurisy gained him an unlimited. Seizing the opportunity, he focused solely on his musical studies and in 1918 graduated with a diploma in composition from the Conservatory of Music in Bologna. He became an astonishingly prolific composer; his musical legacy consists—only in part—of eight operas, five oratorios, six cantatas, twenty-one orchestral works, fifteen concertos, ${ }^{2}$ three ballets, over 400 songs, more than one-hundred choral works (Purcell 1972, 3), forty-two solo piano works, fifteen solo classical guitar works, sixteen chamber works, thirty-three duos set for various instruments, four works for solo organ (Higham 1977, 2), and fifty-one "alphabetical" pieces based on the names of friends and colleagues (Asbury 2005, 3), not to mention the hundreds of film scores he arranged.

Despite the genial quality of his orchestral and piano works and despite the numerous awards he received, it is mainly because of his friendship with Spanish guitarist Andrés Segovia (1893-1987) that Tedesco's music is still heard in today's concert halls. He met Segovia for the first time at the 1932 International Festival of Venice. Segovia, along with Spain's leading composer, Manuel de Falla (1876-1946), praised Tedesco for his Quintetto

${ }^{1}$ Two other undeniable influences reflected in Tedesco's music were the Hebrew Old Testament, and the writings of William Shakespeare, of which he set to music numerous songs and sonnets and composed eleven overtures. For more on Judaic influences in Tedesco’s music see Rosen 1991.

${ }^{2}$ He was the first Italian to write a violin concerto since Paganini (Otero, 34). 
per Pianoforte ed Archi, the piece that Tedesco considered his best work of that period (Otero, 41). Eager to have Tedesco compose a piece for guitar, Segovia left his address in Geneva with Tedesco's wife, Clara. In a letter to Segovia, Tedesco admitted that he had not the remotest idea of how to compose for the guitar. In response, Segovia noted how the guitar is tuned and included two pieces, which he considered quintessential: Fernando Sor's Variation on a theme by Mozart, Op. 9, and Variations sur Folia de España et Fugue by Manuel M. Ponce (Higham, 13). Once he understood the guitar's capabilities, Tedesco composed a set of clever variations titled Variazioni attraverso i secoli, Op. 71 (Variations Across the Centuries). ${ }^{3}$ Upon receiving the first two dances, Segovia wrote back, praising: "It is the first time that I find a composer who immediately understands how to write for the guitar" (Purcell, 3).

Tedesco wrote six more pieces for guitar before fleeing to the United States in 1939: the Sonata in D ("Omaggio a Boccherini”), Op. 77 (1934); Capriccio Diabolico (Omaggio a Paganini), Op. 85 (1935); Tarantella, Op. 87a (1936); Aranci in Fiore, Op. 87b (1936); Variations Plaisantes (“J'ai du bon tabac”), Op. 95 (1937); and his most famous work, the Concerto in D, Op. 99 (1939). ${ }^{4}$ Through Segovia's encouragement and the direct help of Jascha Heifetz, Albert Spalding and Arturo Toscanini, Tedesco and his family safely, and legally, emigrated from Italy, leaving behind his beloved parents and city of Florence. A year later, Heifetz found him employment with a Hollywood film company, and on October 30, 1940 he moved from New York to Los Angeles with hopes of a more stable future.

${ }^{3}$ Variazioni begins with a Baroque-inspired Chaconne, moves on to a Classical-style prelude, proceeds to two nineteenth-century waltzes, and finishes with a jazzy fox-trot-all with modern tonal language and evoking the spirit rather than the letter of their period styles.

${ }^{4}$ Although it is not technically the first guitar concerto of the twentieth century, Tedesco's was the first important concerto; a concert by the Mexican composer, Rafael Adame, preceded Tedesco's by nine years. 
Although the employment was more regular, it was much less satisfying than teaching, and he jokingly referred to it as "Babylonic slavery." When his contract expired, he freelanced for MGM and Columbia studios and produced over 200 pieces a year, all of which he considered terribly mediocre (Otero, 68). In a letter to his brother he noted the following about his work:

Really, none of it is very interesting to me, and least of all the music that I write for films, which (fortunately) I forget as soon as I've written it (or right after I've orchestrated it and recorded it), so that it won't disturb my brain too much. However it's been useful to me, not only as a means of making a living but also as a great exercise in orchestration. (Otero, 75)

Once established in Beverly Hills with his family, Tedesco began to compose once again for guitar. His Serenade, Op. 118, completed in 1943, is a serenata composed for guitar and chamber orchestra "in the purpose, if not in the style, of those of Mozart and Brahms" (Higham, 20). From 1943 until his death in 1968, Tedesco composed at least one work for the guitar almost every year. Among them, the most notable are: the Rondo, Op. 124 (1946); Guitar Quintet, Op. 143 (1950); Romancero Gitano, Op. 151 (1951); the second Guitar Concerto in C (“Concerto Serano”), Op. 160 (1953); Platero y Yo, Op. 190 (1960); 24 Caprichos de Goya, Op. 195 (1961); Les Guitares bien tempérées, Op. 199 (1962); the Concerto for Two Guitars, Op. 201 (1962); and the Sonatina for Flute and Guitar, Op. 205 (1965).

His last major contribution for the guitar, Appunti, preludi e studi per chitarra, Op. 210 (1968), was of a didactic nature. The Italian concert guitarist, Ruggero Chiesa, interested in writing a book on technique for young players that would include pieces of moderate difficulty, asked Tedesco if he would compose the studies for his book. Appunti would be divided into four parts (intervals, rhythm, figurations, and serial compositions) and 
focus on different aspects of technique. Unfortunately, on March 16, 1968, Tedesco died before its completion and only finished the pieces for the first two books, two pieces for the third, and merely sketches for the last book (Wade 2011). And, similar to these sketches, many of Tedesco's works remained only in his head, never to be heard by the rest of the world.

...Everything is in the project state (as daydreams, moreover)...For me it is easy to imagine, but not easy to carry out (because I would like everything to be impeccable), and, lately, it is precisely physical fatigue that holds me back and obstructs me (difficulty in breathing, a weakening of life, hands that seem rusty). Only this little brain of mine goes on, as fresh as ever. Everything goes well until one is seventy. After that, it would be better to stop and simply dream. (Otero, 128-129)

\section{Analysis}

When Alfred Leonard, director of the Los Angeles Music Guild, asked Andrés Segovia to participate in a chamber music concert, Segovia expressed his concern that the guitar did not have very good chamber music repertoire, aside from a few Boccherini quintets and some quartets by Paganini. He agreed, however, to accept the invitation on the condition that Tedesco compose a quintet for the modern portion of the program. Tedesco gladly obliged and completed the quintet within a month (Higham, 56). Segovia and the Paganini Quartet premiered the Quintet for Guitar and String Quartet, Op. 143, closing out the 1951 Music Guild's concert series. The piece, received with great acclaim, was soon recorded and included as a standard piece in Segovia's future concerts.

Tedesco drew inspiration for the Quintet from the standard classical string quartet form explored by Haydn in his later quartets. It is a four-movement work with a fast first movement (Allegro, vivo e schietto), slow second movement (Andante mesto), lively dance third movement (Scherzo allegro con spirito), and an excitingly energetic final movement 
(Allegro con fuoco). The quintet exhibits Spanish influences, such as rasgueado markings, ${ }^{5}$ a Spanish theme in the middle of the second movement, and a Habanera rhythm in the final movement; since his first trip to Spain as a child in 1913, its verdant countryside had enraptured his imagination and left an indelible impression (Otero, 23).

The Allegro, vivo e schietto, regarded by Tedesco as being Schubert-like (Higham, 56) is in sonata form. ${ }^{6}$ The two-part exposition begins with a short motivic introduction, which Higham calls an incipit (56). The first measure establishes a third-related tonal axis as the guitar strums an F-major triad on the first beat, followed on the upbeat by a $\operatorname{Dm} 7$ chord stated in the strings. ${ }^{7}$ Both the F-major and D-minor keys are simultaneously present until an Am7 chord in the fifth measure creates a weak cadence in D-minor; to obfuscate matters further, the presence of $\mathrm{E} b$ in the following measure implies a V7 of $\mathrm{B} b$.

The incipit functions as an opening gesture throughout the movement, introducing the transition, second theme, development section, recapitulation, and the codetta that closes the piece. It not only helps unify the whole but also serves as the germinating element for the first and second themes-labeled $\mathrm{P}$ and $\mathrm{S}$ in the following figures (Higham, 57). Figure 1 illustrates the motivic relationship between the incipit $(\mathrm{Q})^{8}$ — consisting of melodic motion in seconds and thirds contrasted with wide intervallic leaps - and portions of P and S.

${ }^{5}$ Rasgueado is the technique of a quick, rhythmic strumming that is generally associated with Spanish flamenco guitar music.

${ }^{6}$ Neither Castelnuovo nor Higham elaborate on what makes this movement Schubertian, but I suggest a few common traits below.

${ }^{7}$ The concept of tonal axis as an analytical tool was first developed by Bailey 1985 and Straus 1982.

8 "Q" for quelle, meaning "source" in German. 

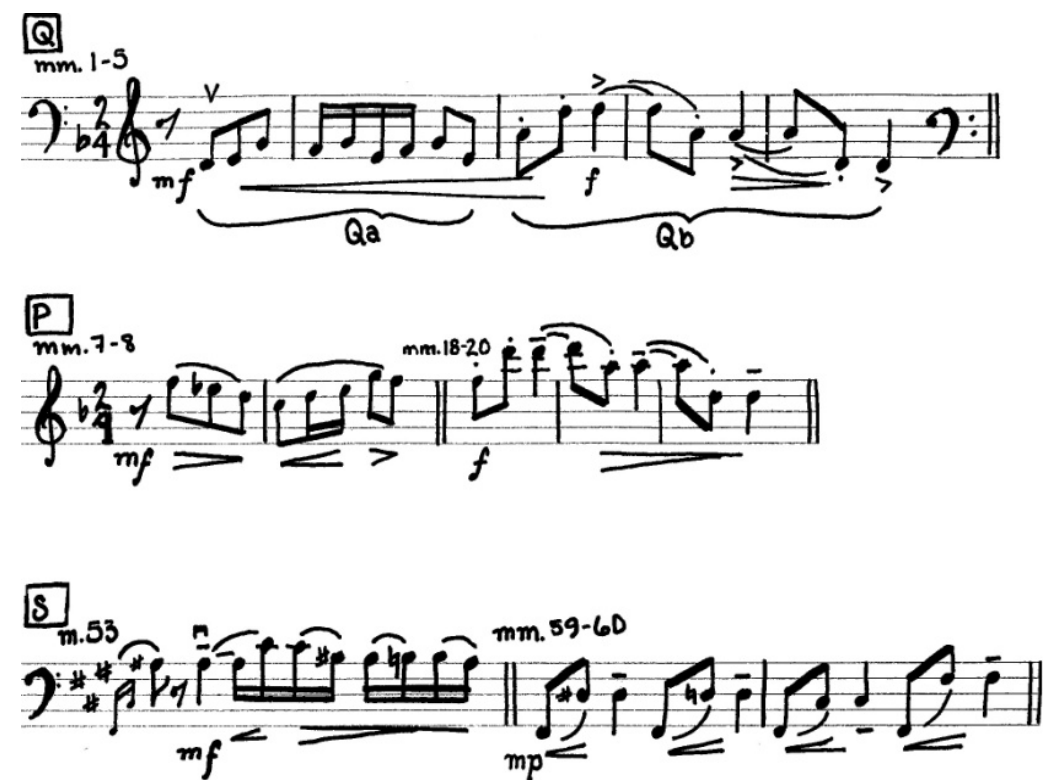

Figure 1. Tedesco: Quintet, $1^{\text {st }}$ movement. Motivic Relationship between $Q, P$ and $S$.

In mm. 6-14, the cello and first violin introduce the first theme canonically at the interval of one measure. In mm. 15-25, the violin and viola complete $\mathrm{P}$ with a contrasting phrase, shown in Figure 2, sequentially arpeggiating a Gm7 chord, leaping up a sixth to $\mathrm{d}^{3}$, and falling an octave via a perfect fourth and fifth, as in $\mathrm{Qb}$.

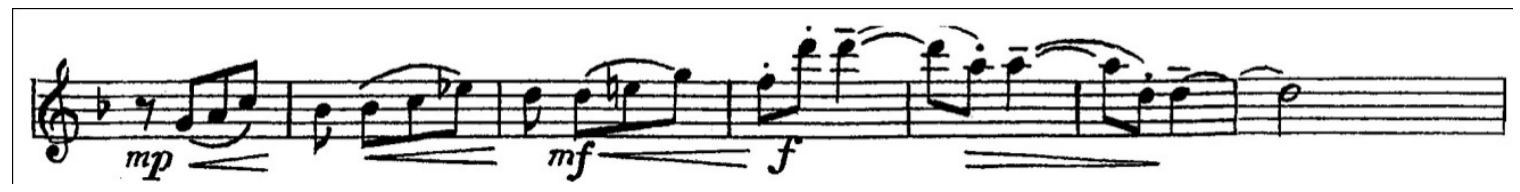

Figure 2. Tedesco: Quintet, $1^{\text {st }}$ movement. Ending of $P$.

At $\mathrm{m} .25$, the incipit returns transposed up a whole step to introduce the transition, which continues with the guitar restating $\mathrm{P}$ at the upper fifth $(\mathrm{mm} .30-41$, at which point the exact transposition breaks off). The music up to this point is tonally unstable: the G minor/E $b$ major axis is suggested at $\mathrm{mm} .28-29$, and the restatement of $\mathrm{P}$ arrives at a 
prolonged $\mathrm{V} 7$ of $\mathrm{B} b$ in $\mathrm{mm} .41-45$, recalling $\mathrm{m} .5$ and suggesting that the submediant $\mathrm{B} b$ will be the key of the second-theme group. Instead — and this is surely one of the moments that Castelnuovo Tedesco had in mind when he characterized the movement as Schubertian —at the last minute the F7 chord is enharmonically reinterpeted as an augmented-sixth chord in the key of $\mathrm{A}$, setting up a $\mathrm{V}_{4-3}^{6-5}$ cadence (mm. 47-48) that ushers in the meltingly lyrical A-major second theme. Schubert, too, was fond of setting up the "wrong" dominant for his lyrical second themes.

Tedesco creates contrast between both themes by changing the character as well as the time signature; $\mathrm{P}$ is allegro and vivace in $2 / 4$, while $\mathrm{S}$ is always più dolce in $4 / 4$. The first violin introduces $\mathrm{S}$, which, as Figure 3 shows, quickly veers off into the third-related key of F\# major (see the cello counterstatement beginning at m. 53). ${ }^{9}$ Tedesco prepares F\# major with a dominant seventh chord on $\mathrm{G}$ in $\mathrm{m}$. 52, enharmonically reinterpreted as a German augmented-sixth chord. F\# major in turn functions as VII\# of G major, preparing a further restatement of $\mathrm{S}$ in that key. (Thus, the large-scale bass plan of $\mathrm{S}$ is essentially A-G-F\#-G.) By $\mathrm{m} .68$, the mode shifts to the parallel $\mathrm{G}$ minor, in which key a repetition of $\mathrm{Q}$ ushers in the development section.

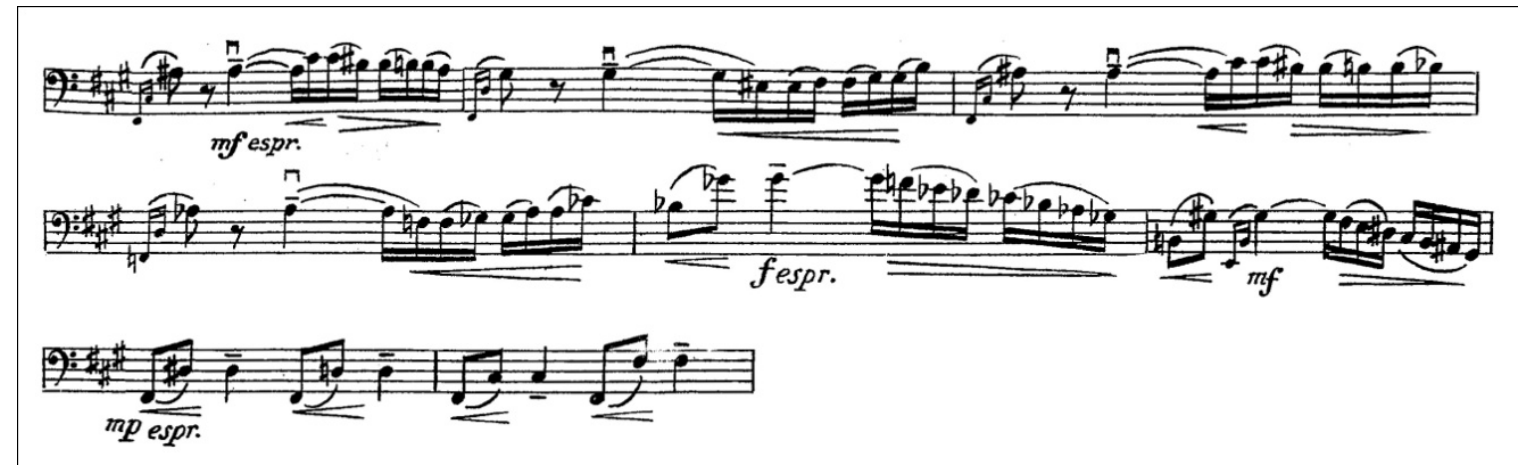

Figure 3. Tedesco: Quintet, $1^{\text {st }}$ movement. Cello counterstatement of S on III\#.

\footnotetext{
${ }^{9}$ The systematic use of third-relations is, of course, another Schubertian trait.
} 
The development section fragments motives found in $\mathrm{Q}, \mathrm{P}$, and $\mathrm{S}$ and combines them. First, Tedesco exploits motives from Q in B b; he then shifts focus to motives from $\mathrm{P}$ and combines both. At $\mathrm{m} .125$, the guitar returns to $\mathrm{S}$ in $\mathrm{G}$ major. A dominant seventh chord on $\mathrm{G}$ leads to a restatement of $\mathrm{S}$ by the first violin in $\mathrm{C}$ major while the guitar accompanies with material derived from Q (mm. 133-140). Figure 4 shows the harmonic plan of the development through m. 140.

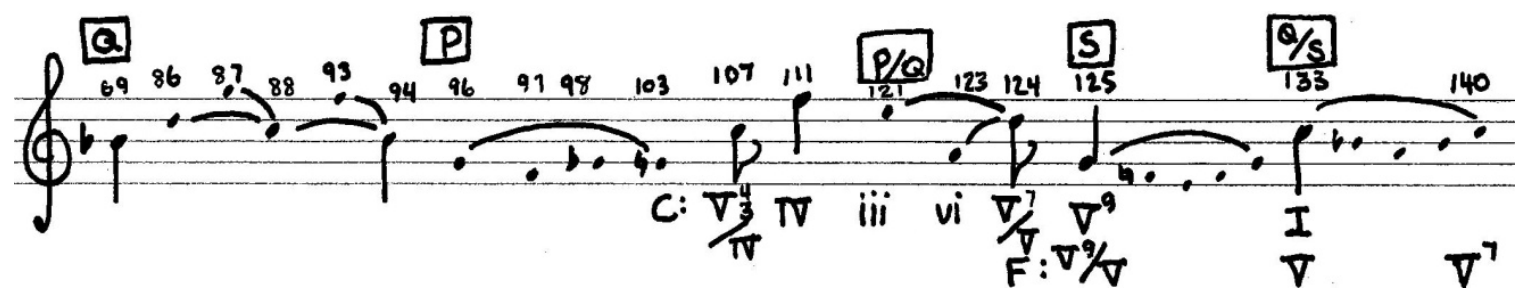

Figure 4. Tedesco: Quintet, $1^{\text {st }}$ movement. Harmonic plan of development.

What follows is a five-measure passage on $\mathrm{F}$ that anticipates the $\mathrm{F} / \mathrm{D}$ tonal access of the recapitulation. The retransition quotes fragment Qa sequentially on F by rising octaves, starting from the cello up to the first violin. The cello and viola statements outline F minor, while the violin statements outline F major. The development ends with the guitar stating Qa sequentially on each member of the F-major triad.

The recapitulation, starting at $\mathrm{m}$. 146, begins with Q, but with the strings playing an octave lower than in the exposition and with the guitar's motivic ascending chords (mm. 3-6) now played descending, imitating the strings. Tedesco focuses on imitation in the recapitulation, but otherwise restates the themes in their original keys with few modal modifications. The first violin introduces $\mathrm{P}$ in the Dorian mode on $\mathrm{D}$, echoed by the viola. The guitar follows in $\mathrm{m} .158$ moving $\mathrm{P}$ down to $\mathrm{C}$ major. After remaining on a $\mathrm{C}$ pedal in 
mm. 166-170, the bass moves up a fourth to $\mathrm{F}$ and cadences in $\mathrm{B} b$ at $\mathrm{m} .172$. At $\mathrm{m} .187, \mathrm{~S}$ is stated first in the strings and then the guitar, as it was in the exposition, except that the keys are now $\mathrm{G}$ major moving to $\mathrm{C}$ major, instead of A major moving to $\mathrm{G}$ major. After a dominant seventh chord in $\mathrm{m}$. 202, Tedesco interpolates Q one last time to close the piece just as it began. The piece ends with an unusual progression in which the tonic F major is embellished by an inverted augmented-sixth chord, B-D b-F-A $b$ (spelled C $b-\mathrm{D} b-\mathrm{F}-\mathrm{A} b$ ), thus concluding the movement with a $\mathrm{C} b-\mathrm{F}$ leap in the bass.

Andante Mesto was Tedesco's favorite of the four movements (Higham, 56). With its second theme subtitled ma dolce e lontano: "Souvenir d'Espagne", this movement speaks to Tedesco's nostalgia for Spain. It showcases the guitar more as soloist with accompanimental strings than any of the other movements.

The movement as a whole is constructed as a sonata-rondo hybrid:

\begin{tabular}{|c|c|c|c|c|c|c|c|c|}
\hline Refrain & Transition & Episode 1 & Refrain & Transition & Episode 2 & Development & Recapitulation & Coda \\
\hline & & & $\mathbf{P}$ & & $2 \mathrm{~S}$ & & $1 S$ & \\
\hline m. 1 & 24 & 33 & 42 & 50 & 64 & 73 & $92 \quad 103$ & 112 \\
\hline i & & $\mathrm{III} \rightarrow \mathrm{V}$ & $\mathbf{i}$ & $\rightarrow \mathrm{V} / \mathrm{F}$ & VII & $\mathrm{v} \rightarrow \mathrm{III} \rightarrow \mathrm{V}$ & $\mathbf{i}$ & $\mathbf{i}$ \\
\hline
\end{tabular}

Tedesco exploits modal ambiguity in the plaintive refrain theme $(\mathrm{P})$. The initial Phrygian-like, four-measure phrase based on a G-minor triad contains both the natural and flattened super-tonic as well as a natural and flattened sub-mediant, establishing the Spanish character that pervades this movement. The primary theme is an expanded twenty-threemeasure sentence:

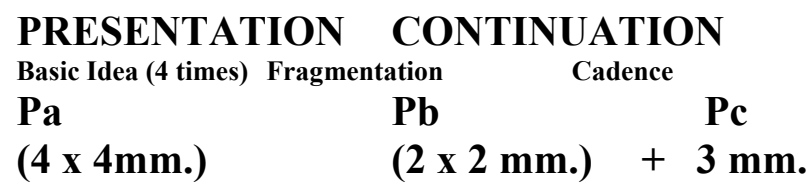


It is constructed of three subphrases, with the last phrase $(\mathrm{Pc})$ arriving at a half-cadential dominant and also prefiguring the first episode. Figure 5 shows the three subphrases.

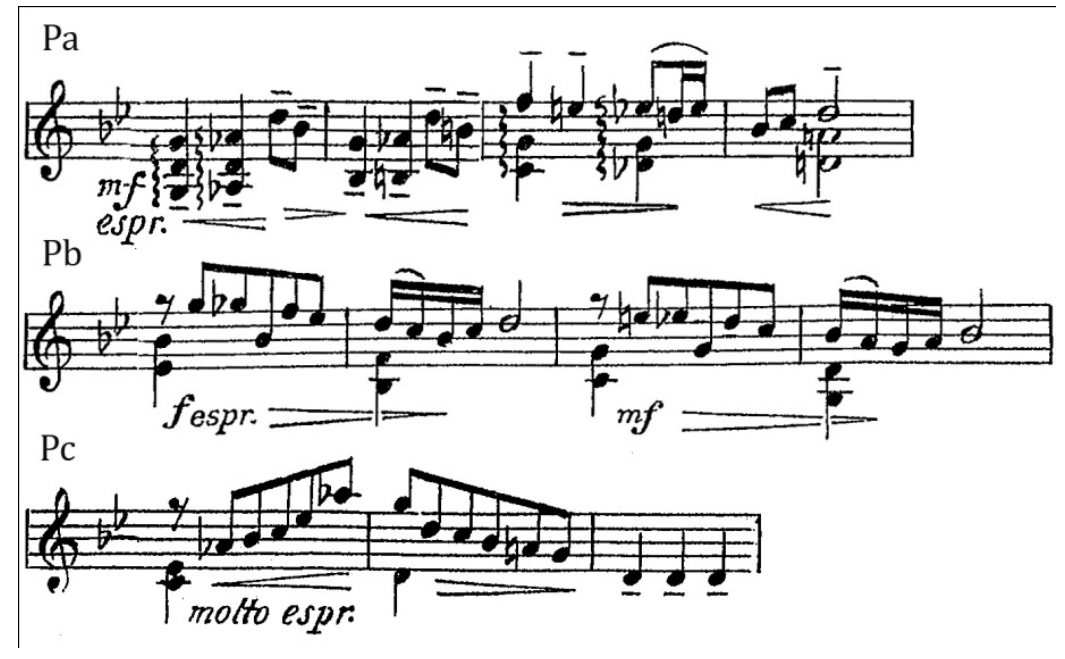

Figure 5. Tedesco: Quintet, $2^{\text {nd }}$ movement. Subphrases of $P$.

To further enhance the Spanish character, the cadence includes a Neapolitan sixth chord as it moves to the dominant.

The transition to the first episode (mm. 24-32) begins with a dominant pedal point, which then moves down via a French augmented-sixth chord to the $\mathrm{B} b$ tonic of the second theme (D-C-C b - B b ). Over this bass progression, the first violin, second violin and viola successively reiterate Pc. In the new key, the cello maintains Pc while the guitar introduces a new triplet figure based on the three repeated notes closing Pc as well as a modified form of Pc in diminution, thus forming the first episode theme (1S).

The return of the refrain theme (P) at m. 42 is shortened; the initial five-bar phrase is heard just once, instead of four times. P returns in the first violin partially echoed by the viola, while the guitar maintains figuration introduced in the first episode, thereby blurring the formal boundary. The last subphrase of the refrain theme $(\mathrm{Pc})$ is replaced by a transition, 
based on $\mathrm{Pb}$, that connects the tonic $\mathrm{G}$ minor to the dominant of the F-major second episode $\left(\mathrm{Gmin}-\mathrm{F}^{6}-\mathrm{E} b^{7}-\mathrm{D}^{6}-\mathrm{D} b^{6}-\mathrm{C}\right)$.

Figure 6 illustrates that the first violin's melodic theme in the second episode $(2 S)$ is a simplified derivation of $1 \mathrm{~S}$; it also derives from the sixteenth-note motive in the second measure of $\mathrm{Pb}$. Measures 55-57 form an introduction to the Spanish theme (m. 58) that dominates the second episode; here, the guitar, along with the material derived from $\mathrm{Pb}$ and $1 \mathrm{~S}$, introduces new triadic material $(2 \mathrm{Sb})$.

The second episode moves harmonically from VII (F major) to V (D major), which arrives at $\mathrm{m} .64$ and is prolonged by the entire ensemble through $\mathrm{m} .69$. In $\mathrm{mm} .70-72$, still on $\mathrm{V}$, Tedesco highlights the soloistic nature of the guitar in this movement by introducing an unaccompanied guitar solo, marked quasi cadenza, based on $2 \mathrm{Sb}$.

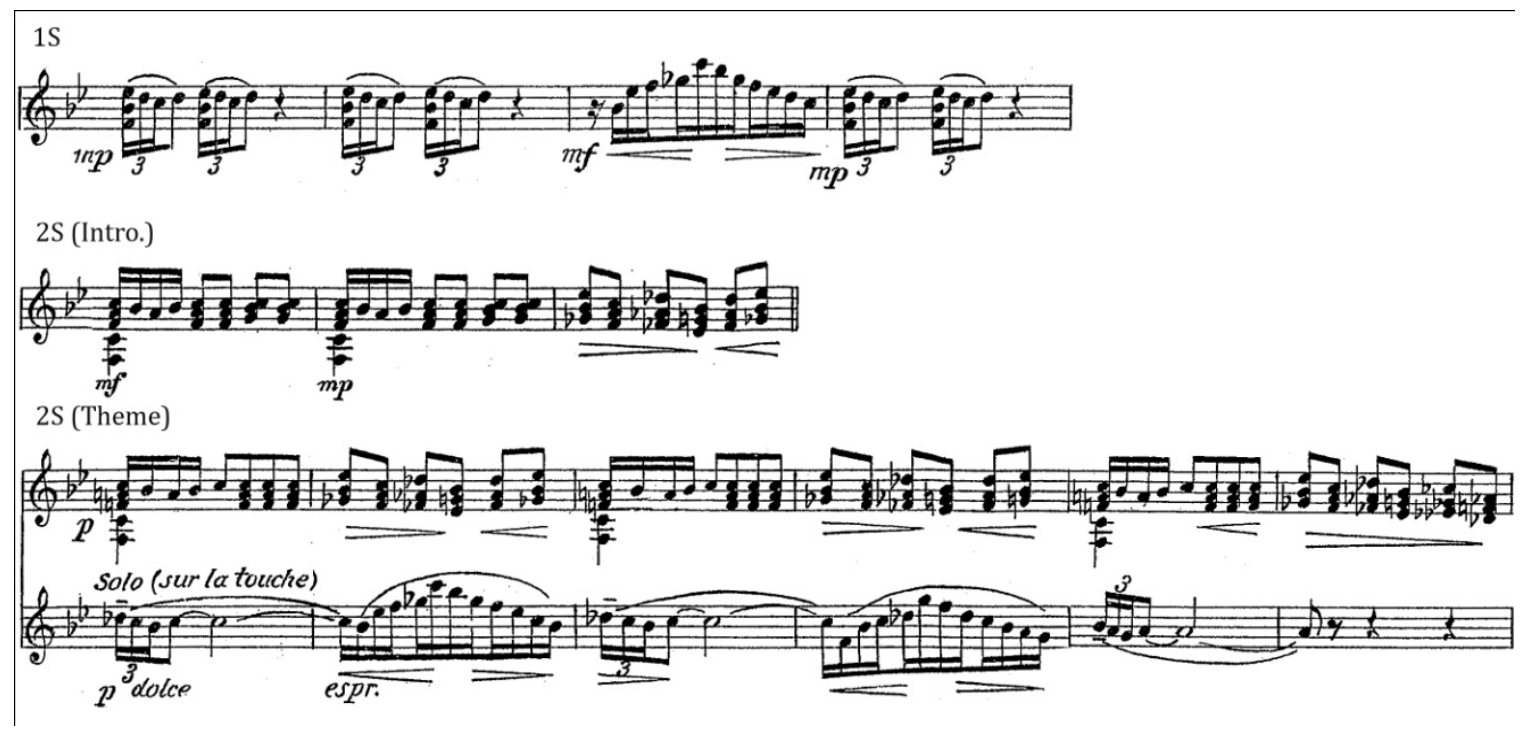

Figure 6. Tedesco: Quintet, $2^{\text {nd }}$ movement. Derivation of $2 S$ from $1 S$.

This cadenza closes the second episode and introduces a developmental passage that prolongs the home dominant; in effect both the cadenza and the developmental episode are interpolated between the $\mathrm{V}$ at $\mathrm{m} .69$ and the tonic return of the refrain at $\mathrm{m} .92$. Within this 
developmental interpolation, Tedesco explores new textures on $\mathrm{Pa}$. It is first stated in $\mathrm{D}$ minor by the guitar in octaves, supported by the cello playing pizzicato ( $\mathrm{mm}$. 73-76). The phrase is then repeated by the quartet in A-minor, with the second violin playing pizzicato in octaves mimicking the guitar (mm. 77-79). A brief transition ( $\mathrm{mm} \mathrm{80-83)} \mathrm{based} \mathrm{on} \mathrm{S2} \mathrm{and}$ comprised of tritone-related seventh chords on B and F, which combined form an octatonic collection, elides the conclusion of the phrase.

After the transition, a modified version of Pa returns on $\mathrm{B} b$ in the first violin and second violin (mm. 84-87). Figure 7 shows the modifications undergone in $\mathrm{Pa}^{\prime}$. In this variation, the first violin plays $\mathrm{Pa}$, juxtaposed with $2 \mathrm{~S}$ material in the guitar. Meanwhile, the second violin introduces an arpeggiated sextuplet pattern whose top-most notes carry the melodic phrase. Also, the leap between mm. 85 and 86 is shortened to a fourth and the leap between mm. 86 and 87 is widened to a fifth. Originally these intervals were reversed (cf. Figures 5 and 7).

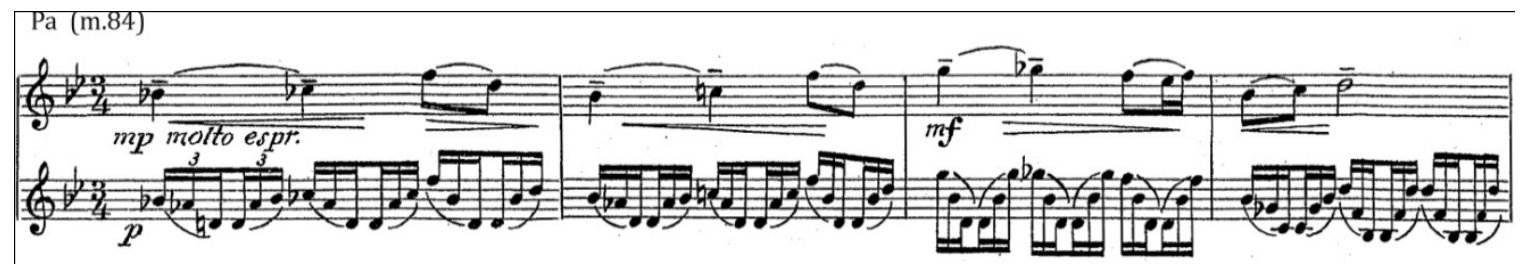

Figure 7. Tedesco: Quintet, $2^{\text {nd }}$ movement. Variant of Pa in development.

Measures 88-91 present yet another variant of $\mathrm{Pa}$, this time with the theme played in octaves in the Guitar and doubled by the viola, with the first violin playing the $2 \mathrm{~S}$ material. This juxtaposition of $\mathrm{Pa}$ and $2 \mathrm{~S}$ takes place over a bass line connecting $\mathrm{B} b$ to $\mathrm{V} 7$ of the home key, in preparation for the recapitulation. In this repetition of $\mathrm{Pa}$, the importance of the 
intervallic reversal is revealed; the cadence closing the phrase, which would have ended on $\mathrm{F}$ major with the original intervals, instead ends a minor third lower on D major.

After $\mathrm{P}$ and $1 \mathrm{~S}$ are both repeated in tonic, the movement closes with a final, serene and dream-like restatement of $\mathrm{Pa}$. The strings playing dolce e lontano (sweetly and distant) in harmonics and the guitar playing misterioso end the piece on a Picardy third.

From one dream to another, the Scherzo allegro con spirito alla Marcia begins with an ethereal texture similar to that in the coda of Andante Mesto. After the viola trills down a chromatic octave from $\mathrm{d}^{2}$ to $\mathrm{d}^{1}$, the violins foreshadow the scherzo theme in harmonics over a tremolo pedal on the dominant of $\mathrm{G}$ minor. Up to $\mathrm{m}$. 17, the persistent dominant tremolo imparts an introductory atmosphere with motives in the violins and viola that prefigure the scherzo and first trio theme. True to his affinity for modal changes, Tedesco presents the eight-measure scherzo theme $(\mathrm{P})$ in the parallel major of the introduction, first in the guitar, then in the strings. Figure 8 illustrates the scherzo theme as played by the guitar and its three motivic subdivisions.

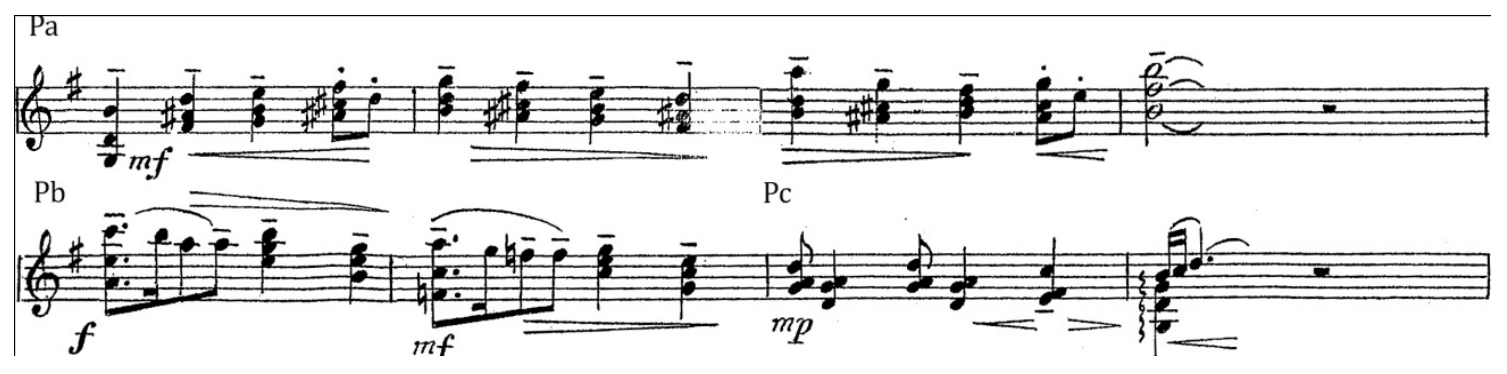

Figure 8. Tedesco: Quintet, $3^{\text {rd }}$ movement. Scherzo theme.

The first of two trio sections begins at m. 33. Although quite divergent, the first trio theme (S) complement's the scherzo's burlesque character and maintains the gaiety of the march. Beginning in the flattened submediant key and ending in the tonic minor, $\mathrm{S}$ is 
characterized by the lack of a strong first beat and, according to Higham (79), "elements of surprise," including leaps, abrupt modulations, and lack of a balanced phrase structure. A brief four-measure transition (mm. 51-54), in which motives from $\mathrm{S}$ and $\mathrm{P}$ are juxtaposed, shifts the mode back to $\mathrm{G}$ major for a return to the scherzo.

The second trio section (2S), beginning at m. 77, borrows the Habanera-like rhythmic motive from Pc (compare Figure 9 to the last two bars of Figure 8).

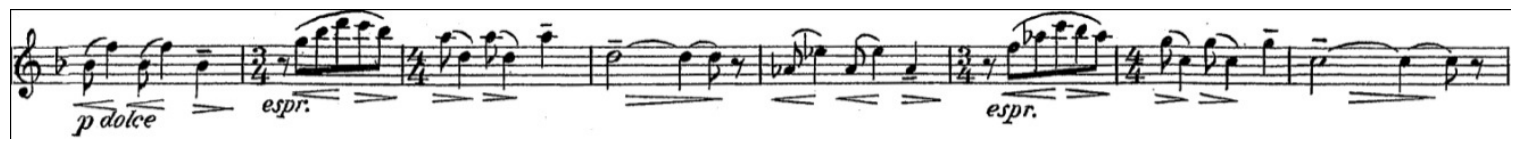

Figure 9. Tedesco: Quintet, $3^{\text {rd }}$ movement. Second trio.

Presented by the violins in $\mathrm{F}$ major, $2 \mathrm{~S}$ is an eight-measure modulating period in mixedmeter consisting of a four-measure phrase repeated one whole step lower and built on a ii-VI sequence of chained seventh chords. This trio theme provides more contrast than $1 \mathrm{~S}$ does since it not only contains mixed meter but also has more an air of nobility than whimsy. At m. 55 , the guitar repeats $2 \mathrm{~S}$ a fifth lower and extends it with a short cadenza on an altereddominant chord (with flattened fifth) leading into an elongated variation of the introductory material to return to G tonality (mm. 99-107). Motives from the trios are juxtaposed over an entire restatement of $\mathrm{P}$ followed by a coda revisiting previous motivic material. Almost as an afterthought, Tedesco includes a coda within the coda-introductory material returns for three measures only to be wittily interrupted by the guitar with a b VII7-I cadence.

Allegro con fuoco provides a suitably climactic finale for this emotional quintet. It is a tarantella in rondo form with three episodes, including a languid habanera to contrast with the lively rondo theme (Otero, 85). Beginning in G-minor, the twelve-measure rondo theme 
(R) is an expanded sentence built on three subphrases. As illustrated in Figure 10, the first and third phrases are complementary by intervallic inversion (fifths become fourths) while the second phrase contrasts by virtue of its scalar motive.

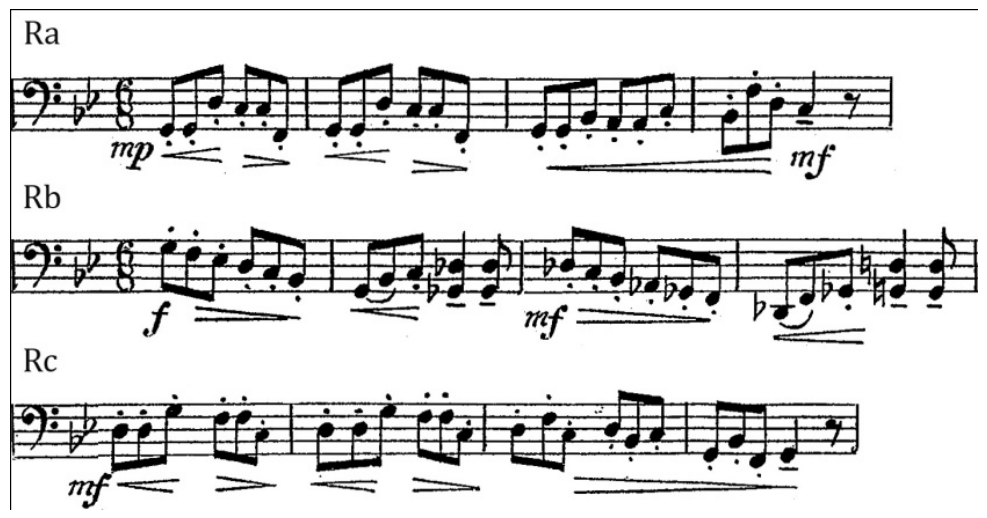

Figure 10. Tedesco: Quintet, finale. Refrain theme.

The phrases are easily divisible into short fragments to facilitate expansion by sequential repetition, such as in the guitar's Eingang (mm. 29-38) to the solo statement of the refrain (mm. 39-54). Figure 11 shows this Eingang; the last measure of the example is the first measure of the refrain proper. Tedesco expands the refrain not only by prefixing it with an Eingang but also by interpolating four measures between Rb and Rc (mm. 47-50).

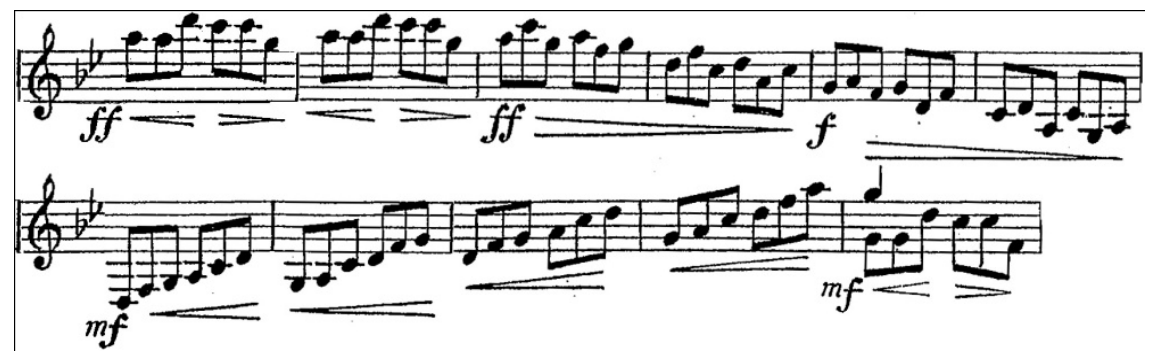

Figure 11. Tedesco: Quintet, finale. Eingang to solo refrain (mm. 29-38).

The first episode (1S) at mm. 55-98 moves from the dominant minor to the dominant major (D minor to D major) largely by way of third relations [Dm-FM-Am-(G7)-CM/m- 
FM-DM]. 1S forms a 3+5 asymmetric period that contains two contrasting subphrases similar to R. The first subphrase derives directly from Rc, merely interpolating a dottedquarter note pitch repetition:

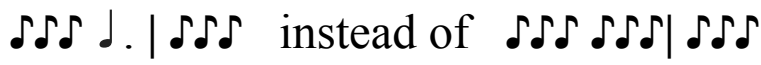

The second subphrase is stepwise and more lyrical. The $1 \mathrm{~S}$ theme is stated four times, by turn in the viola, second violin, first violin, and guitar. Each of the first three statements begins on $\mathrm{A}$, in successively higher octaves $\left(\mathrm{a}, \mathrm{a}^{1}, \mathrm{a}^{2}\right)$, but with third-related harmonies (D-F-A) supporting each entry, necessitating changes of accidentals, although Tedesco preserves the same melodic contour for all three statements. The guitar entrance, coinciding with a move up yet another third (to C major, prepared by the G7 in $\mathrm{mm} .73-78$ ), breaks with the preceding pattern by transposing $1 \mathrm{~S}$ up a fifth.

With canonic entries two measures apart, the rondo theme returns partially in the viola and second violin and fully in the first violin (mm. 99-114) in successively higher octaves. Indeed, it is a recurring strategy in this movement for themes to be presented in imitation, first in the viola and then successively through the upper parts.

A rhythmic motive borrowed from the dactylic figure in $\mathrm{Rb}$ becomes the basis of a short transition (mm. 115-126) leading into a second episode (2S) in G b major, later respelled as $\mathrm{F} \#$ major (VII\#). The melodic theme in $2 \mathrm{~S}$ is built of a repeated three-measure phrase. Figure 12 shows that that, harmonically, the viola statement consists of the following repeated, open-ended harmonic progression: F\#M-D7 (or VII\# $3-\mathrm{V} 7$, in terms of the overall G tonality). ${ }^{10}$ The second violin statement resolves the viola statement by beginning with

\footnotetext{
${ }^{10}$ Tedesco spells it GßM, but we must understand it as VII\#, which in turn is part of a bass unfolding of the dominant (F\#-D).
} 
G7 harmony, which Tedesco reinterprets enharmonically as an augmented-sixth chord, resolving it to F\#7. Thus, locally, the second violin statement can be understood as B: Ger 6 -V7. The first violin statement expands a B-major ${ }_{4}^{6}$, which resolves to F\#7 when the guitar enters with the theme at $\mathrm{m}$. 149. The guitar statement consists in the progression F\#7-D7. If one combines all five statements, one arrives at large-scale progression shown in Figure 13:

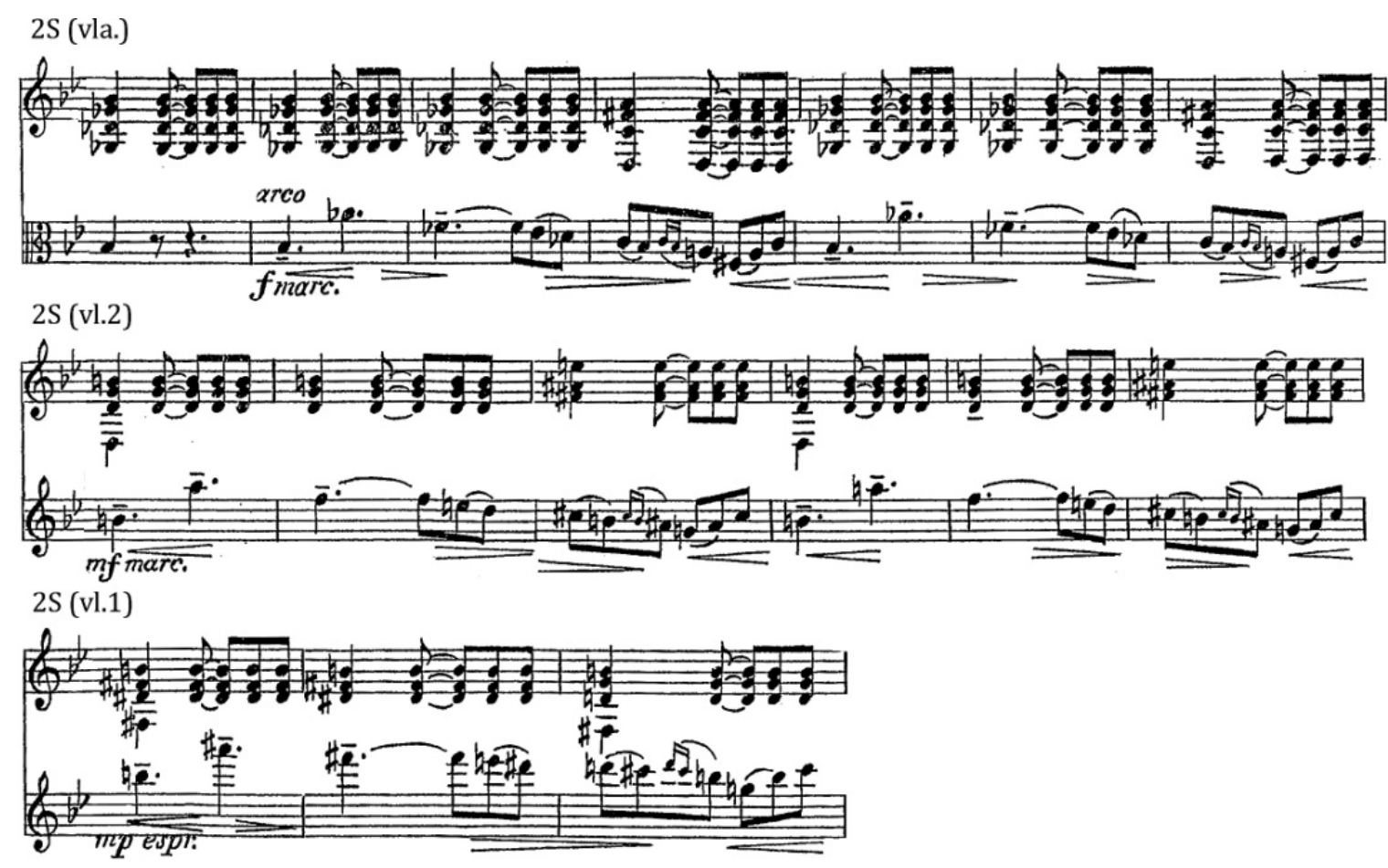

Figure 12. Tedesco: Quintet, finale. Second episode.

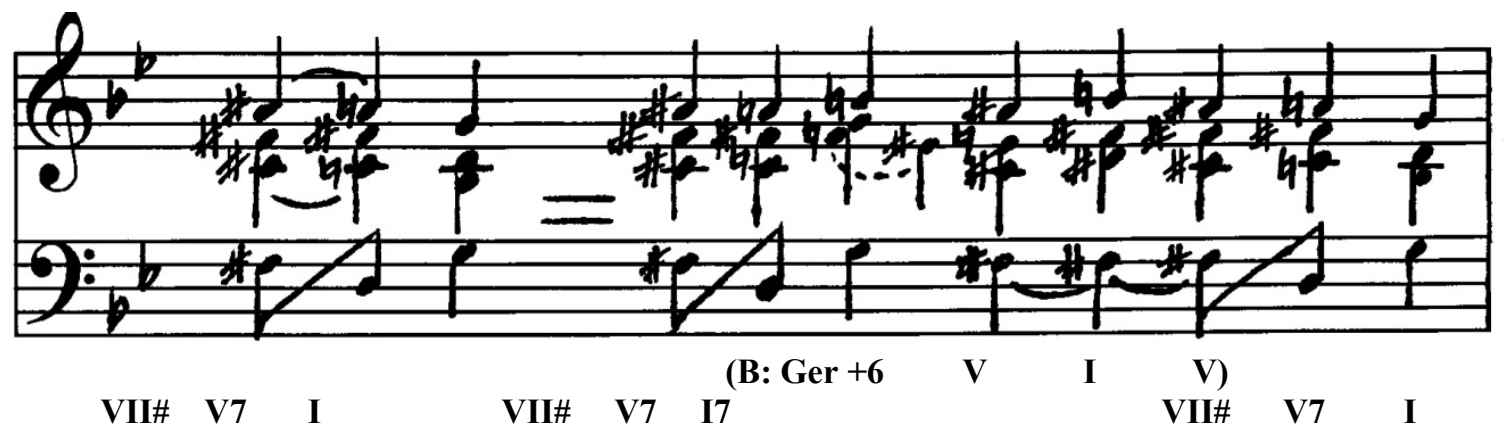

Figure 13. Tedesco: Quintet, finale. Second episode progression. 
The third occurrence of R at m. 158 is entirely inverted and, when heard in the guitar, is juxtaposed over the accompanimental motive of $2 \mathrm{~S}$. Tedesco changes the texture when the guitar takes on the inverted theme by having the strings accompany with pizzicato articulation as if to mimic the guitar's part in $2 \mathrm{~S}$. Ending on a half cadence in G, the third refrain leads to the third and longest episode at m. 198.

Switching to $2 / 4$ meter, the character changes from fiery to dolce e semplice (come una canzone popolare (sweet and simple like a popular song). To create even more contrast, this theme begins in the violins rather in the viola, which imitates at the interval of one measure. This third episode (3S) in G major is based on an eight-measure sentence with a simple harmonization. Figure 14 shows the simplicity of this entirely diatonic and tonal theme. (Every previous theme has exhibited both chromaticism and modality).

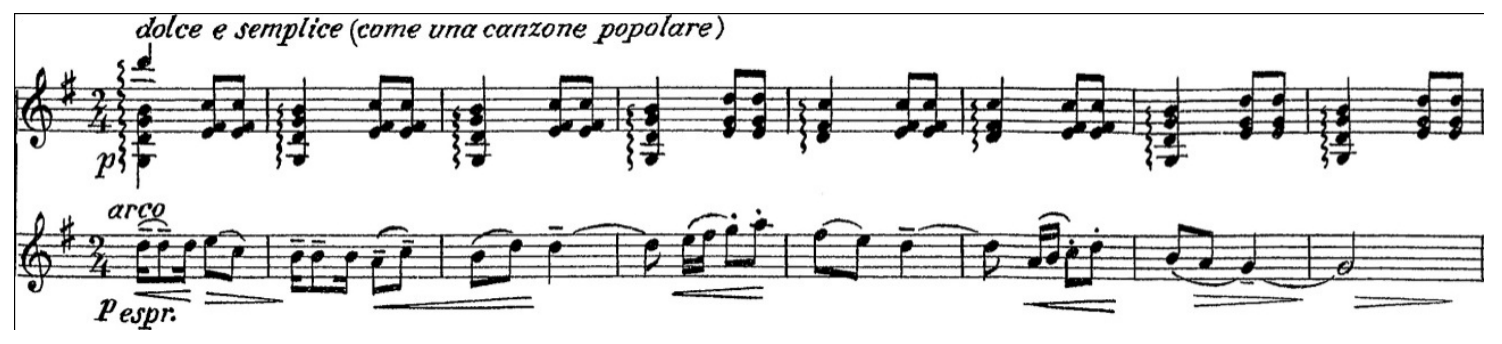

Figure 14. Tedesco: Quintet, finale. Third episode.

After the second statement of $3 \mathrm{~S}$, a brief transition features a motivic subject from the habanera treated canonically in the first violin and viola over an E b pedal in the cello. This passage ushers in the sweetest statement yet of $3 \mathrm{~S}$ in $\mathrm{A} b$, with the strings playing the theme in a homophonic texture against flowing sixteenth-note scales and arpeggios in the guitar. Halfway through the theme, in a breathtakingly beautiful chromatic modulation, Tedesco reinterprets A $b$ major as $b$ II of $\mathrm{G}$ major, allowing the third episode to end in the home tonic. The transitional canonic material, previously over an Eß pedal, returns as a solo guitar 
passage (a piacere quasi recitative) and now over a V7 harmony in G. Rather than return to G major for the final restatement of $\mathrm{R}$, the solo ends with a deceptive cadence on the flattened sub-mediant.

The rondo theme returns at $\mathrm{m}$. 238, now over an $\mathrm{E} b$ pedal, beginning first in the cello and subsequently moving upward through the strings to the first violin. A pedal on D b follows and falls a semitone lower to $\mathrm{C}$ preparing an arrival in $\mathrm{F}$ major for the extended coda at $\mathrm{m} .263$. All of the various themes, with the exception of $1 \mathrm{~S}$, return in this summarizing coda. Tedesco begins by juxtaposing $3 \mathrm{~S}$ in the violins over $\mathrm{R}$ in the lower strings and after eight measures reverses the themes for another eight measures. At m. 279, there follows a canonic restatement of $2 \mathrm{~S}$ in $\mathrm{G} b$ (thus recalling both the VII\# harmony and the thematic material of the second episode). As in the second episode, the VII\# harmony leads to V7, here prolonged for 12 measures (mm. 284-295) and embellished by A b major chords. The repeated b II-V7 progressions in mm. 284-290 recall the third episode. This dominant prolongation prepares the finale rondo return in the main key. The rondo's theme returns first in the strings, which juxtapose it over the inverted form, and then in the guitar supported by reiterated snippets of the Habanera theme in the strings. The coda ends with an emotional tour de force- - a crescendo poco a poco as the R, 2S and 3S motives are superimposed for four measures and an accelerando in the ensuing final four bars. The quintet, as if in one voice, declares the final $\mathrm{G}$ major chord. 


\section{Leo Brouwer: Concerto No. 3, Elegiaco}

\section{Biography}

Leo Brouwer is one of the most significant composers and proponents for the classical guitar. Journalist Therese Saba observed that before Leo published his series of studies, Etudes Simples, there was far too little "in the way of repertoire that could bridge the gap between the accessible student level and professional-level contemporary repertoire" (Saba 2008, 37). Not only has he made great contributions to the solo guitar repertoire, but also in the field of duos, trios, quartets, quintets, chamber pieces and concertos for the instrument. Leo felt that although there were wonderful pieces written for the guitar from previous centuries, there were severe gaps in its repertoire compared to that of orchestral instruments and piano (McKenna 2012). He not only believed their to be gaps in its repertoire, but also musically substantial counterparts to the concertos of Beethoven, Chopin or Bartok, even going so far as to criticize the highly revered concertos of Villa Lobos and Joaquin Rodrigo for their "shortness and lack of motivic development" (Castilla 2009, 2). Thus in the light of this disparity, he endeavored to fill this musical void with new works for guitar that were, for the most part, inexorably tinged with his Afro-Cuban musical heritage.

In an interview with Paul Reed Century, one of the foremost researchers of Brouwer's music, he expressed his longing for grander repertoire:

Where was the Bartók for the guitar? There was no Bartók for the guitar... Where was the Concerto for Cembalo and Instruments that de Falla did? There was no Octet like Stravinsky's, no Danse Sacrée and Danse Profane of Debussy for harp and strings ... all this music was a discovery for me... and I said, I'm going to compose for guitar and strings; I did Danzas Concertantes....(Reed 1985, 9)

Brouwer's compositional style has evolved from nationalistic music in the 1950s and 1960s involving popular music infused with Afro-Cuban rhythms to atonal and aleatoric 
compositions in the mid-1960s to 1970s. El Decamaron Negro, composed in 1981, represents the beginning of his third stylistic period. In several interviews, Brouwer has referred to this new style as "neo-simplistic," (Saba, 39) due to his return to classic forms and use of minimalism. He also conceded the terms neo-Romantic (Cooper 1985, 13) and hyperRomantic since his current works exhibit a "sophisticated Romantic feeling," or rather, clichés of nineteenth-century music (McKenna 2012). More than three decades have passed by and unfortunately, despite the popularity of his pieces among musicians, analyses yet put forth leave much to be desired. Except for a few enlightening interviews and a handful of theoretical dissertations showing merely a glimmer of the full radiance of his creativity, there yet remain a vast number of unearthed gems in the quarry of Brouwer's post-modern music.

\section{Analysis}

In her 1998 dissertation on the language of Brouwer's music, Loyda Dumille Camacho proposed that Brouwer's new style could not adequately be studied using standard analytical approaches but rather by using an approach similar to generative grammar in which musical phrases are grouped into units similar to words in spoken language (as pioneered by Fred Lerdahl in the 1980s) (Dumille 1998, 6). Contrary to Camacho's proposal, Felipe Espinosa Wang demonstrated that, although not an obvious solution, the axis system developed and used by Ernő Lendvaï in analyzing Bartók’s music could adequately be applied to Brouwer's new music (Espinosa 2008, 18). ${ }^{11}$ The axis system functions upon the premise that tones and chords related by a minor third or tri-tone are

${ }^{11}$ See Wang for an in depth analysis of Concerto Elegiaco using the axis system as well the uncanny relationship this concerto shares with the Fibonacci series and the golden mean. 
functionally interchangeable as tonal substitutes - the tri-tone being the stronger relation.

Not only has Brouwer returned to the use of tonality, but classical forms as well. According

to Brouwer, avant-garde music was dead and a new expressionism would replace it:

That avant-garde epoch of mine is a little bit gone - a little bit too old, maybe. I think that in the near future music is going to get very romantic once more. It has been too brainy, too cold, too mathematical - too mastermind...It is a moment for opening doors, for alerting people, for cleansing music... No more Boulez! No more Stockhausen! It's finished!...Twentieth-century music has to go somewhere other than the avant-garde. (Cooper 16)

Commissioned in 1985 by the BBC for guitarist Julian Bream, Concerto Elegiaco is Brouwer's third concerto and marvelously exemplifies the economical use of thematic material and creative extended tonal language of his neo-simplistic style. The basic material for the entire concerto is stated within the first twenty bars; however, through a variety of techniques he maintains interest and develops the concerto linearly in an organic manner. Brouwer emphasizes quartal harmony throughout the majority of the concerto, and predominantly uses homophonic texture, especially when the orchestra accompanies the guitar. For transitions, however, Brouwer often presents thematic material in the form of polyphony or cluster chords. ${ }^{12}$

The orchestration is particularly interesting, consisting of strings, timpani, side-drum, tom-tom, marimba, and glockenspiel. The sound of myriad percussive timbres combined with strings presents a sonic spectrum very similar to the guitar, and it is highly plausible that Brouwer had in mind the idea of replicating the colorful sonority of the guitar. One clear example of this is found at the very beginning of the second movement. Figure 15 is an excerpt from this movement, starting from m.10, in which the orchestra mimics the sound of

${ }^{12}$ Brouwer use polyphonic texture in only two occasions, both in the first movement: as segue out of the exposition into the closing-theme group ( $\mathrm{mm}$. 57-67) and immediately after the development transitioning into the recapitulation (mm. 108-114). 
a guitar arpeggiating a chord by means of one section playing pizzicato (a percussive effect) and the other section playing arco, sustaining the plucked note. Reaffirming this perceived mimicry, the guitar enters with the same arpeggio while the orchestra sustains the chord.

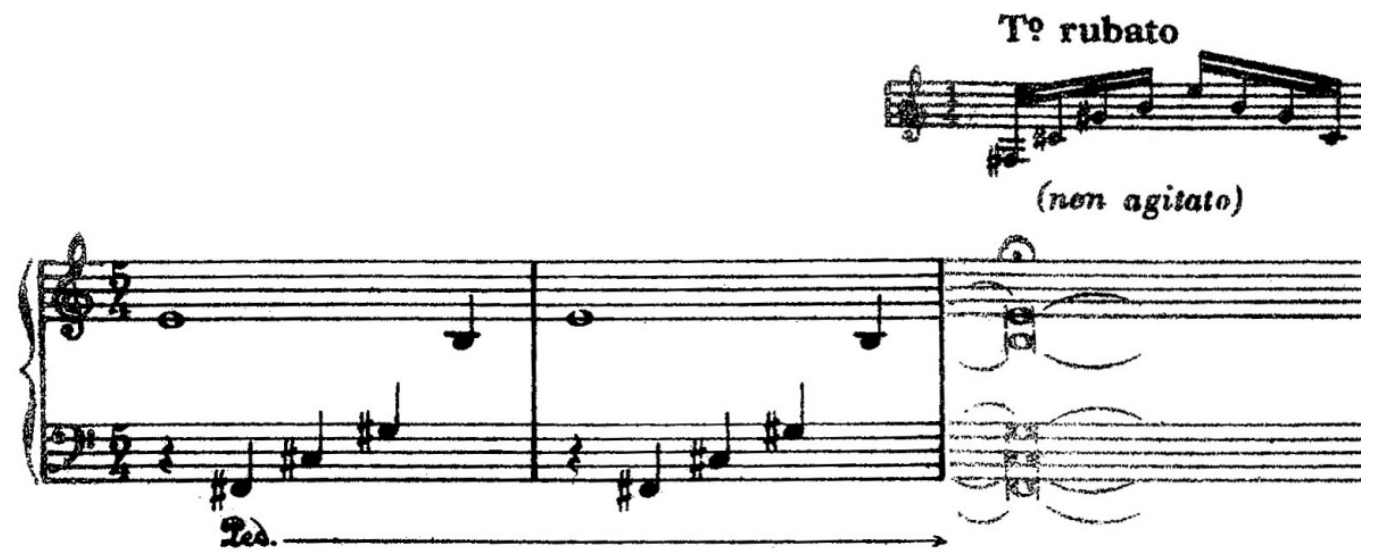

Figure 15. Brouwer: Elegiaco. Second Movement. Orchestra mimics the guitar.

During lectures and interviews, Brouwer often addressed the effect non-musical figures had in his development as a composer. In the late 1970s and again in the late 1980s, he gave a lecture titled "La Composicion Modular" (Modular Composition) where he expressed the importance of proportion and structure. According to Brouwer, the SwissGerman painter Paul Klee was one of the most influential artists on his own views of structure within a composition. Klee's paintings are often described as being musical since his concepts of color and form often have musical correlations. One particular concept used in Brouwer's lectures is hierarchical recursive relations within structure: "what defines the whole defines the parts, and vice-versa" (Brouwer 2004, 74). ${ }^{13}$ Figure 16 is Brouwer's own visual elaboration of this principle observed in Klee's works. In this example, the overall

\footnotetext{
13 “...lo que es común al todo es común a las partes y viceversa.”
} 
structure of the tree (the macrocosm) is not only represented in its roots but also in a leaf (the microcosm).

\section{Paul Klee}

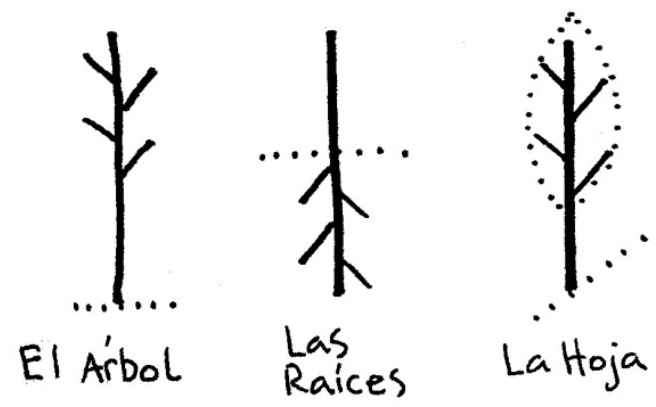

Figure 16. Principle of structure found in Paul Klee's works.

Brouwer follows this principle in the first movement of Elegiaco. The primary theme (P) heard in the first opening measure of the concerto becomes a skeleton upon which the transition and closing-theme group of the exposition are fleshed out over thirty measures before the development section. Figure 17 presents both $\mathrm{P}$ and a bass reduction of the orchestral accompaniment from measures $57-88$. The bass is inverted compared to $\mathrm{P}$, and the final interval is transformed from a minor $6^{\text {th }}$ to a major $6^{\text {th }}$ (B $b$ is the counterpole of the movement's tonic key of E). ${ }^{14}$

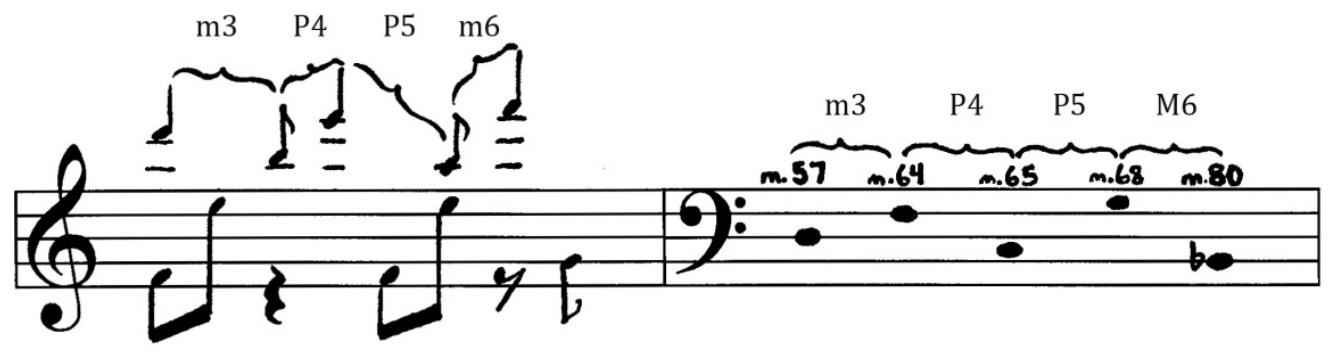

Figure 17. Brouwer: Elegiaco. First Movement $m .1$ and bass reduction of mm. 57-88.

${ }^{14}$ Within Lendvaï's axis system, counterpole is the term used to indicate the tritone substitute of a key. 
Brower not only uses this principle within the harmonic structure of the first movement, but also incorporates it within the overall plan of the concerto - the true macrocosm. The first and third movements exhibit typical sonata form, albeit the later showing a slight difference from the former with its monothematic exposition and extended coda. The improvisatory-like second movement is in ternary form with each section alternating between orchestra and soloist, but predominantly focusing on the guitar. The macrocosm mirrors each of these forms. In a concise diagram, musicologist Bryan Townsend shows how the entire concerto can be viewed as a single movement in modified sonata form, citing the indication of attacca subito between movements as one of many pieces of evidence to support this theory. Figure 18 below presents the formal plan of the whole concerto as one movement (Townsend 2000, 20). 

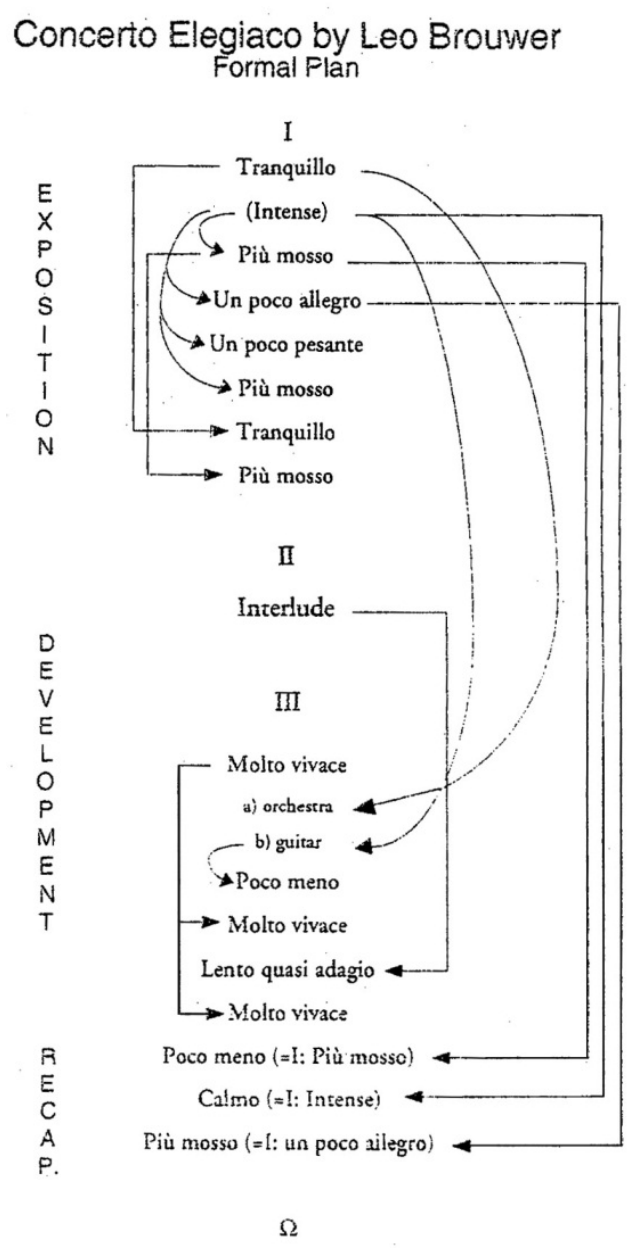

Figure 18. Brouwer: Elegiaco. Formal Plan.

With this context in mind, the surprisingly short and seemingly out-of-place second movement now reveals a much more fitting role within the whole framework - that of an extended cadenza. If the individual form of each movement is considered (sonata-ternarysonata), Elegiaco concurrently exhibits ternary form (A-B-A') as well as sonata.

Elegiaco is a prime example of the retrospective yet gradual evolution of music as it presents postmodern language within classical form. This is not to say that the present qualitatively overshadows the past — that would be impossible — but rather that the past is reinvented in the light of a new context. Furthermore, Brouwer borrows material from 
previous concertos as well as literally quotes, in the second movement, a passage from the eighteenth study of Etudes Simples (Castilla, 76). By doing so, he breathes new life into not only the past of the humble guitar, but its future as well. 


\section{References}

Asbury, David S. "20th Century Romantic Serialism: The Opus 170 Greeting Cards of Mario Castelnuovo-Tedesco.” PhD diss., University of Texas at Austin, 2005.

Brouwer, Leo. Gajes del Oficio. La Habana: Editorial Letras Cubanas, 2004.

Castilla Peñaranda, Carlos Isaac. "Leo Brouwer's Estudios Sencillos for Guitar: Afro-Cuban Elements and Pedagogical Devices." PhD diss., University of Southern Mississippi, 2009.

Century, Paul Reed. "Idiom and Intellect: Stylistic Synthesis in the Solo Guitar Music of Leo Brouwer.” Master's thesis, University of California Santa Barbara, 1985.

Cooper, Colin. "Chanson de Geste: Leo Brouwer and the New Romanticism.” Classical Guitar 3 (June 1985 ): 13-16.

Dumille Camacho, Loyda. "Interactions, Cross-Relations, and Superimpositions: the Musical Language of Leo Brouwer.” PhD diss., University of Pittsburgh, 1998.

Espinosa Wang, Felipe. "Lenguaje Musical de Leo Brouwer en el Concierto \#3 para Guitarra y Orquesta.” Master's thesis, Pontifica Universidad Javeriana, 2008.

Higham, Peter Anthony. “Castelnuovo-Tedesco's Works for Guitar.” Master's thesis, University of Alberta, 1977.

Mckenna, Constance. "An Interview with Leo Brouwer." http://www.angelfire.com/in/eimaj/interviews/leo.brouwer.html (accessed 1/20/2012)

Otero, Corazon. Mario Castelnuovo-Tedesco: His Life and Works for the Guitar. United Kingdom: Ashley Mark Publishing Company, 1999.

Purcell, Ronald C. "Mario Castelnuovo-Tedesco and the Guitar," Guitar Review 37, (Fall 1972): 2-4.

Rosen, Harriette Mildred. "The Influence of Judaic Liturgical Music in Selected Secular Works of Mario Castelnuovo-Tedesco and Darius Milhaud." PhD diss., University of California, 1991.

Townsend, Bryan. "The Formal Plan of Leo Brouwer's Concerto Elegiaco (1986)." Classical Guitar 18, no. 5 (January 2000): 18, 20.

Wade, Graham. "The Relevance of Mario Castelnuovo-Tedesco (1895-1968)." 1995. http://www.egta.co.uk/content/ct (accessed 7/27/2011).

Wassily Saba, Therese. “Leo Brouwer's New Guitar Concerto.” Classical Guitar 26, no.8 (April 2008): 36-40. 